\title{
INVESTIGACIÓN
}

Recibido: 15/03/2021 --- Aceptado: 20/05/2021 --- Publicado: 03/01/2022

\section{IDENTIFICACIÓN DE LAS FAKE NEWS QUE SE PUBLICAN EN LA EDICIÓN EN PAPEL DE UN DIARIO PROVINCIAL EN LA ERA DE LA DESINFORMACIÓN DIGITAL DE TRUMP Y EL INICIO DEL COVID}

\author{
Identification of fake news published in the paper edition of a provincial \\ newspaper in the era of trump's digital disinformation and the start of covid. \\ From global to local
}

Jesús Mula-Grau. Universidad Miguel Hernández. España. jmula@umh.es

Belén Cambronero-Saiz. Universidad Internacional de La Rioja. España. belen.cambronero@unir.net

\section{Cómo citar el artículo:}

Mula-Grau, J. y Cambronero-Saiz, B. (2022). Identificación de las fake news que se publican en la edición en papel de un diario provincial en la era de la desinformación digital de Trump y el inicio del COVID. Vivat Academia. Revista de Comunicación, 155, 23-38. http://doi.org/10.15178/va.2022.155.e1329

\section{RESUMEN}

Las fake news se han convertido en un problema en la sociedad de la información generalista y debe su preeminencia, en buena medida, a la democratización de las redes sociales y a la polarización de fuerzas de distinto índole. Pero más allá de los canales digitales, existe un público, en este caso de corte local-provincial, que sigue las noticias como tradicionalmente ha hecho: principalmente a través de su diario de referencia, en papel. Este trabajo analiza, cuantitativa y cualitativamente, los contenidos relacionados con las fake news aparecidos en la versión impresa del Diario Información, entre el 3 de febrero de 2020, inicio de la campaña electoral en EE UU y la aparición del primer caso de coronavirus en España, dos hechos claros que conducen directamente a noticias en origen o destino falsas, hasta el 21 de enero de 2021, día este último siguiente al inicio de la era Joe Biden. El objetivo es intentar conocer si el acerbo debate y el protagonismo de las fake news en los canales digitales tienen un traslado proporcional a las páginas de este rotativo y si son temas prioritarios para la persona lectora. El estudio deja claro que frente al bombardeo y el 
Mula-Grau, J. y Cambronero-Saiz, B.

Identificación de las fake news que se publican en la edición en papel de un diario provincial en la era de la desinformación digital de Trump y el inicio del COVID

ruido en torno a las fake news en el social media, en la prensa de papel predomina una reflexión sosegada, un análisis del problema y una denuncia clara y avalada en contra de este tipo de mensajes. Y lo que es más importante: casi no es noticia para el papel.

PALABRAS CLAVE: Fake news - Trump - desinformación - posverdad - covid infodemia - comunicación - bulos - infoxicación.

\section{ABSTRACT}

Fake news has become a problem in the general information society and owes its preeminence, to a large extent, to the democratisation of social networks and the polarisation of different kinds of forces. But beyond the digital channels, there is a public, in this case of a local-provincial nature, which follows the news as it has traditionally done: mainly through its newspaper of reference, in print. This paper analyses, quantitatively and qualitatively, the contents related to fake news appearing in the printed version of Diario Información, between 3 February 2020, the start of the US election campaign and the appearance of the first case of coronavirus in Spain, two clear events that lead directly to fake news in origin or destination, until 21 January 2021, the latter day following the start of the Joe Biden era. The aim is to try to find out whether the acerbic debate and the prominence of fake news in digital channels have a proportional transfer to the pages of this newspaper and whether they are priority issues for the reader. The study makes it clear that, compared to the bombardment and noise surrounding fake news in social media, in the print press there is a predominance of calm reflection, analysis of the problem and a clear and endorsed denunciation of this type of message. And what is more important: it is almost no news for the paper.

KEYWORDS: Fake news - Trump - disinformation - post-truth - covid - infodemic communication - hoaxes - infoxication.

\section{IDENTIFICAÇÃO DAS FAKE NEWS QUE SE PUBLICARAM NA EDIÇÃO EM PAPEL DE UM DIÁRIO PROVINCIAL NA ERA DA DESINFORMAÇÃO DIGITAL DE TRUMP E O INÍCIO DA COVID}

\section{RESUMO}

As fake news têm se transformado em um problema na sociedade da informação generalista e deve sua preeminência, em boa medida, a democratização das redes sociais e a polarização de forças de diferentes origens. Mas além dos canais digitais existe um público, neste caso, de corte local-provincial, que segue as notícias como tradicionalmente, principalmente através do seu jornal de preferência, no papel. Este trabalho analisa, quantitativa e qualitativamente os conteúdos relacionados com as

Vivat Academia. Revista de Comunicación. 2022, n 155, 23-38 
Mula-Grau, J. y Cambronero-Saiz, B.

Identificación de las fake news que se publican en la edición en papel de un diario provincial en la era de la desinformación digital de Trump y el inicio del COVID

fake news que aparecem na versão impressa do Diario información, entre o 3 de fevereiro de 2020, início da campanha eleitoral dos EUA e a aparição do primeiro caso de coronavírus na espanha, dois fatos claros que conduzem diretamente as notícias de origem e destino falsas, até o dia 21 de janeiro e 2021, dia este que dá início a era de Joe Biden. O objetivo é tentar conhecer se o debate amargo e o protagonismo das fake news nos canais digitais tem um traslado proporcional às páginas dos jornais, e se são temas prioritários para os leitores. O estudo deixa claro que perante o bombardeio e o ruído em torno das fake news e as redes sociais na mídia social, na imprensa predomina uma reflexão sossegada, uma análise do problema e uma denúncia clara e forte contra este tipo de mensagens. E o que é mais importante: quase não é notícia para o papel.

PALAVRAS CHAVE: Fake news - Trump - desinformação - pós verdade - covid infodemia - comunicação - bulos - infoxicação.

\section{INTRODUCCIÓN}

El 25 de enero de 2021 la red social Twitter lanzaba Birdwatch, una novedosa herramienta en pruebas pensada para que los propios usuarios puedan combatir la desinformación y denunciar fake news. El experimento piloto comenzó en Estados Unidos con un reducido grupo de personas que podían realizar las verificaciones e incluso añadir notas para refutar posts falsos o aquellos con una voluntad de manipular. Casi al unísono el todopoderoso Google, en torno al 16 de enero, admitía haber suprimido contenido de noticias locales en un experimento llevado a cabo en Australia. Entre ambas fechas, en concreto el 20 de enero, Donald Trump, la mayor personificación de las fake news, abandonaba la Casa Blanca, poniendo así fin, en parte, a cuatro años en los que durante su mandato (2017-2021) las noticias falsas se convirtieron en noticia per se.

Considerado posiblemente por la opinión pública como uno de los mayores emisores de noticias engañosas (Twitter le cerró la cuenta el 9 de enero de 2021), a la vez que, sorprendentemente, se presentaba como un gladiador contra la desinformación, acusando a veteranos medios de comunicación (sobre todo al New York Times y al Washington Post) de difundir pseudoinformación, mentiras y de manipular a las audiencias, Trump ha sido uno de los presidentes más mediáticos y que más repercusión global ha tenido, además de por su cargo, por sus polémicas vinculadas al coronavirus, entre otras cuestiones (San Miguel y Sanchez-Gey, 2020).

El término fake news es un concepto anglosajón que se refiere a lo que en la sociedad española se conoce también como noticias falsas. En estos momentos engloba a toda presunta noticia que, en definitiva, se emite o se repite sin contrastar, la más de las veces emanada desde la mala fe o cuando menos la ignorancia, que se configura más bien como un bulo y que ahora, gracias a las redes sociales, se 
Mula-Grau, J. y Cambronero-Saiz, B.

Identificación de las fake news que se publican en la edición en papel de un diario provincial en la era de la desinformación digital de Trump y el inicio del COVID

convierte en viral y llega a todo tipo de públicos conectados para un consumo y digestión rápidos.

Andrea Renda recuerda que las fake news afectan a la opinión pública al generar «una capa gruesa de "ruido"» que genera confusión (2018, p.13), mientras que para McIntyre fake news es una forma moderna de propaganda (2018, p.127). María Luisa Cárdenas y David Polo (2019, p.147) hablan de "infoxicación ciudadana" para advertir que hemos recorrido el trayecto desde una situación tradicional de escasez de información a otra de absoluto desbordamiento de datos en el presente.

McNair señala que "las noticias siempre han sido criticadas por ser parciales, plagiadas, tergiversadas, fabricadas, ficticias y, sí, falsificadas" (2018, p.17), mientras engloba las fake news en una coyuntura que coincide con el auge de los populismos y los nacionalismos y el desprestigio de las élites y los medios de comunicación.

La posverdad, seno de la mentira y la desinformación, invade las sociedades democráticas occidentales, sin casi posibilidad de combatirla, en estrecha relación con las fake news, la tecnología y sobre todo la política (Keyes, 2004; Alterman, 2004).

Los medios de comunicación influyen sobre la actitud y las tomas de posición de la ciudadanía. Por ejemplo: cambiar normas sociales, hacer recapacitar sobre decisiones electorales, carreras políticas y medidas económicas, apostar por determinados valores, presentar determinados roles y sus calificaciones, variar el rumbo de los conflictos y movilizar a la opinión pública, entre otros. Es decir, la información de masas, el periodismo (y cada vez más las redes sociales) pueden producir y producen efectos sobre el sistema. El hecho de informar contribuye a configurar una opinión pública en una sociedad. Así, los mass media contribuyen a transformar el modelo de sociedad en la que vivimos. Ya en 1922 Walter Lippmann abordaba la concepción de estereotipo y la creación de un modelo de opinión pública que depende de los medios. Según Lippmann, los medios de información son, por tanto, una fuente primaria, aunque no única, de las imágenes y de las ficciones que tenemos en nuestras mentes y con las que se llega a formar opinión pública (Rubio, 2009).

Además, los medios de comunicación delimitan la agenda de temas sobre los que los ciudadanos van a discutir; legitiman a unos actores y puntos de vista en detrimento de otros; y emiten juicios y valoraciones que constituyen los principales marcos de las discusiones de los gobernados. Esto enlaza con la conocida teoría de la agenda-setting o establecimiento de la agenda, que vienen a explicar el impacto, la presión o la influencia en la opinión pública por parte de los medios de comunicación y que comenzó a plantearse a finales de los 60. En resumidas cuentas, esta teoría viene a indicar que los medios nos dicen sobre qué temas pensar y, por tanto, sobre qué pensar. Porque lo que sabemos del mundo en numerosas ocasiones es lo que los medios nos cuentan, por cómo nos lo cuentan, e ignoramos lo que nos dejan de contar. 
Mula-Grau, J. y Cambronero-Saiz, B.

Identificación de las fake news que se publican en la edición en papel de un diario provincial en la era de la desinformación digital de Trump y el inicio del COVID

Algunos autores, sin embargo, moderan el alcance electoral efectivo de fake news que han sido difundidas a través redes sociales, y subrayan el papel que ejercen de corrector los medios tradicionales (Allcott y Gentzkow, 2017). Otros investigadores, en cambio, consideran que el incremento en volumen de las noticias falsas y la posverdad en los últimos años viene a socavar también los estándares de calidad y la tradicional credibilidad de los medios de comunicación y periodistas (Lewandowsky, Ecker y Cook, 2017).

Vosoughi et al. (2018) trabajaron a partir de 126.000 rumores publicados en la red social Twitter de 2006 a 2017, con un impacto estimado cercano a los tres millones de usuarios. Su estudio reveló que las fake news llegaron a una audiencia comprendida entre las mil y los cien mil integrantes, mientras que las noticias auténticas con bastante dificultad alcanzaron al millar. La mentira llegó más lejos y más velozmente que la verdad y estos investigadores creen que dos factores, la novedad y las reacciones emocionales del público destinatario, es decir, la identificación personal a partir de las creencias o prejuicios de uno y las ganas de creer en parte o todo el bulo, prenden la mecha de la propagación (Ruchansky et al., 2017).

Murolo (2019) identifica la posverdad como una idea, un imaginario, un acerbo de representaciones sociales y/o sentidos previamente incorporados por las audiencias y desde donde son posibles fake news que refieren a esa idea, afirmándola o ampliándola

La sociedad tiene hoy en día acceso a ingente información, pero no tiene a mano ni tiempo ni herramientas inmediatas para hacer un cribado de comprobación. La crisis económica de 2008 y con ello la imparable reducción de periodistas en las redacciones que se ha agravado aún más con las consecuencias de la pandemia, junto con el auge de internet, las redes sociales y el periodismo ciudadano, ha conducido a que el lector desconfíe cada vez más de los profesionales, de los medios y de sus informaciones, según Costa Sánchez (2011).

En este sentido tampoco hay que perder de vista que solo un 14 por ciento de los españoles es capaz de distinguir una "fake news", aunque un 59,5 por ciento piense que pueden hacerlo, según los resultados del "I Estudio sobre el Impacto de las Fake News en España", realizado por la empresa de investigación social y estudios de mercado Simple Lógica, en colaboración con la Universidad Complutense de Madrid (2017).

Sin embargo, aún queda un pequeño reducto de lectores, la más de las veces de edad madura, poco proclive a informarse por las redes sociales o escasamente ducho con las nuevas tecnologías, que prefiere saber lo que pasa en su barrio y en el mundo a través de su periódico local de cabecera. "A diferencia de los periódicos digitales, los lectores buscan en los escritos que les jerarquicen y seleccionen unos hechos, que se los interpreten y que les permitan identificarse con lo que representa un periódico por el que pagan" (Fernández, 2010). Representa una audiencia que además de información requiere de interpretación, opinión y, por tanto, tener acceso a distintos puntos de vista, algo que se lo brinda en muchas ocasiones las tribunas o columnas

Vivat Academia. Revista de Comunicación. 2022, nº 155, 23-38 
Mula-Grau, J. y Cambronero-Saiz, B.

Identificación de las fake news que se publican en la edición en papel de un diario provincial en la era de la desinformación digital de Trump y el inicio del COVID

que jalonan las páginas a lo largo de las distintas secciones: "La columna puede combinar como ningún otro género periodístico de opinión la calidad literaria con la rotundidad de las opiniones, la imaginación artística engarzada con esa realidad ideológica o sentimental que quiere el escritor compartir. La columna no vive sujeta a la más inmediata actualidad" (Casals, 2000).

Si bien estos lectores son fieles al medio y otorgan una confianza muy alta a la veracidad de las noticias ligada a una cabecera asociada a la seriedad, un sesgo determinado y el buen periodismo, no es menos cierto que su número se va reduciendo mes tras mes por diversas causas que no son objeto de este estudio.

\section{OBJETIVOS}

La meta de esta investigación es conocer qué fake news se convierten en noticia para una persona lectora de un diario provincial/local de España coincidiendo con la campaña electoral estadounidense más tensa de los últimos años $\mathrm{y}$, a la vez, con la aparición y evolución de la pandemia por el covid. Ambos acontecimientos han prodigado aún más la aparición de esta desinformación y con ello la polémica y la preocupación por el alcance de las fake news. Además, como reacción, todo ello ha dado lugar a acciones para intentar poner coto, no solo por parte de organizaciones privadas (en España por ejemplo está desarrollando un papel relevante Newtral, constituida en octubre de 2017, o Maldita, lanzada en 2018, entre otras empresas periodísticas), sino también desde las propias administraciones públicas. Por qué es noticia una fake news, incluidas las de ámbito internacional y nacional, para un lector local, nos preguntamos, así como deseábamos comprobar si es cierto que al margen de las redes sociales e internet llega ese "ruido", si efectivamente es capaz de trascender el mundo digital e impactar incluso en el papel. Y a raíz de todo ello saber cómo se traslada al lector más tradicional por decirlo de algún modo.

\subsection{Objetivo general}

El objetivo de esta investigación es realizar un análisis pormenorizado de los contenidos relacionados con las fake news aparecidos en el Diario Información, periódico líder de la provincia de Alicante, entre el 3 de febrero de 2020, inicio de la campaña electoral en EE UU y cuando en España había el primer y único afectado por coronavirus -un turista alemán en las Islas Canarias. Desde el inicio del brote (31 de diciembre) hasta el 3 de febrero, se habían notificado 17.383 casos confirmados y 362 fallecimientos, de los cuales, 361 en China y un caso en Filipinas, una persona que procedía de la ciudad de Wuhan, según nota de prensa del Departamento de Seguridad Nacional del Gabinete de la Presidencia del Gobierno de España, y el 21 de enero de 2021, día este último siguiente a la toma de posesión de Joe Biden como presidente de Estados Unidos y con España con un total de 2.456.675 casos de COVID-19 y una cifra total de fallecidos de 55.041, según el balance oficial, ofrecido por el Centro de Coordinación de Alertas y Emergencias Sanitarias.

\subsection{Objetivos específicos}

Vivat Academia. Revista de Comunicación. 2022, nº 155, 23-38 
1. OE1. Establecer el tipo de noticia que generan las distintas temáticas relacionadas con las fake news.

2. OE2. Establecer el porcentaje de protagonismo de estas noticias en el periodo de estudio.

3. OE3. Analizar el tratamiento que la noticia hace de las noticias falsas (denuncia, crítica y manipulación, entre otras).

4. OE4. Analizar las características y el tratamiento que la noticia hace de la/s persona/s y/o los hechos vinculados con las fake news.

\section{METODOLOGÍA}

Este trabajo tiene un enfoque metodológico mixto al incorporar metodologías cualitativas y cuantitativas para la consecución de los objetivos. Para alcanzar los dos primeros objetivos se aplican análisis cuantitativos de frecuencia y para los dos últimos análisis cualitativos de contenido. En este caso, una vez extraídos los artículos que cumplieron los criterios de inclusión y exclusión recogidos en el epígrafe 3.3, (interesaban los que versaran directa o indirectamente sobre los conceptos que pusieran en relación pares como covid y/o Trump con uno o varios de estos términos: fake news, infoxicación, posverdad, bulos, pandemia, desinformación, noticias falsas, elecciones EE UU e infodemia) se seleccionaron aleatoriamente diez de ellos para su clasificación por parte del autor de este trabajo para elaborar una plantilla de análisis.

\subsection{Objeto de estudio}

Diario Información es el periódico líder aboluto de ámbito provincial y único impreso de sus características en la provincia de Alicante.

Diario Información ofrece entre 36 y 68 páginas de lunes a domingo (debido a la pandemia ha reducido su paginación). A su vez, casi la totalidad de los contenidos en papel se vuelcan en su web, continuamente actualizada, aunque no ocurre así a la inversa por, claramente, la limitación de espacio en el papel.

El diario cuenta habitualmente con dos ediciones comarcales: Alicante, y Elche y Vega Baja, pero excepcionalmente puede presentar una edición única por acontecimientos muy relevantes, o incluso pasar a tres ediciones en caso de eventos concretos.

Según el propio diario (12/04/2020), Información cuenta con 158.000 lectores de media diaria en su edición impresa, datos a partir del último informe del Estudio General de Medios (EGM) hecho público por este medio. El EGM atribuye una cuota de mercado en toda la provincia de Alicante del 68,3\%. Este periódico vende más y tiene más audiencia que el resto de medios impresos juntos que también se venden en esta provincia alicantina. 
Mula-Grau, J. y Cambronero-Saiz, B.

Identificación de las fake news que se publican en la edición en papel de un diario provincial en la era de la desinformación digital de Trump y el inicio del COVID

En marzo de 2020 alcanzó los 8.459.619 usuarios únicos mensuales en su edición digital. El lector medio de Información es un hombre casado, de entre 45 y 64 años, que ejerce como sustentador principal de su familia y tiene empleo, con estudios de Bachillerato o COU, y que vive en poblaciones de más de 10.000 habitantes. Mientras tanto, en la edición digital los porcentajes se invierten, hasta el punto de que seis de cada diez lectores son mujeres y la edad media es inferior: el grueso de los usuarios tiene entre los 25 y los 54 años.

Además, este diario hace un volcado de sus contenidos de papel a la web y, a su vez, los enlaza a las redes sociales, sobre todo Facebook y Twitter, la cual no es ajena a esta ceremonia de la confusión (Rodríguez-Ferrándiz, 2019) dado que es una herramienta dotada de mucha potencia en el caso de la comunicación política en pre campañas y campañas electorales (Arceneaux y Weiss, 2010; Jackson y Lilleker, 2011) ya que se ha convertido absolutamente como una de las redes sociales que mayor número de bulos cuantifica frente a otras como Facebook o Instagram.

\subsection{Variables y categorías de estudio}

Este trabajo analiza el tipo de noticia y la sección que ocupa; quiénes son los actores y quiénes los protagonistas que acaparan la noticia; los lugares donde ocurren, así como cuáles son los hechos que recoge la información publicada sobre fake news y cómo es el tratamiento informativo que se otorga.

Para ordenar y clasificar los datos, se ha elaborado una plantilla ex profeso de análisis de acuerdo con un sistema categorial. Siguiendo a Pérez Serrano (1984, p.83) la formación del sistema categorial es la fase más significativa, ya que «refleja directamente el propósito del investigador y la teoría subyacente que organiza el estudio; además de que constituye uno de los escollos más difíciles de salvar y en donde ha de ponerse a prueba toda la creatividad del científico».

El sistema categorial de codificación diseñado para esta investigación está formado por cuatro categorías generales o básicas: 1) Artículo; 2) Características del artículo; 3) Características que se dan o contexto de la fake news; y 4) Espacio que ocupa en la edición impresa (habitualmente las primeras páginas suelen tener más "valor" que las posteriores, y las impares y en color, más que las pares y en blanco y negro).

Tres de las cuatro categorías generales se dividen en subcategorías: 
Mula-Grau, J. y Cambronero-Saiz, B.

Identificación de las fake news que se publican en la edición en papel de un diario provincial en la era de la desinformación digital de Trump y el inicio del COVID

Tabla 1. Categorías y subcategorías de análisis

\begin{tabular}{|c|c|c|}
\hline Categorías & Subcategorías 1 & Subcategorías 2 \\
\hline \multirow[t]{21}{*}{ Artículo } & \multicolumn{2}{|l|}{ Fecha } \\
\hline & \multicolumn{2}{|l|}{ Página } \\
\hline & \multirow[t]{5}{*}{ Tipo } & Información \\
\hline & & Opinión \\
\hline & & Interpretación \\
\hline & & Entrevista \\
\hline & & Publicidad \\
\hline & \multirow[t]{14}{*}{ Sección } & Portada \\
\hline & & Contraportada \\
\hline & & Editorial \\
\hline & & Opinión \\
\hline & & Cartas \\
\hline & & Local/Municipal \\
\hline & & Provincial \\
\hline & & Nacional \\
\hline & & Internacional \\
\hline & & Política \\
\hline & & Sucesos y Tribunales \\
\hline & & Deportes \\
\hline & & Suplementos \\
\hline & & Cultura/Sociedad \\
\hline \multirow[t]{7}{*}{ Características del artículo } & \multicolumn{2}{|c|}{ Protagonista/s principal/es } \\
\hline & \multicolumn{2}{|c|}{ Tratamiento informativo de la fake new o enfoque } \\
\hline & \multicolumn{2}{|l|}{ Circunstancias } \\
\hline & \multirow{4}{*}{$\begin{array}{l}\text { Localidad o Localización a la que se } \\
\text { refiere la noticia }\end{array}$} & Europa \\
\hline & & España \\
\hline & & $\begin{array}{l}\text { Comunidad } \\
\text { Valenciana }\end{array}$ \\
\hline & & Alicante \\
\hline \multirow{10}{*}{$\begin{array}{l}\text { Características que se dan acerca } \\
\text { de la fake news }\end{array}$} & \multicolumn{2}{|l|}{ Covid } \\
\hline & \multicolumn{2}{|l|}{ Trump } \\
\hline & \multicolumn{2}{|l|}{ Elecciones EE UU } \\
\hline & \multirow{7}{*}{$\begin{array}{l}\text { Presencia o ausencia de justificación a } \\
\text { favor o en contra }\end{array}$} & Denuncia \\
\hline & & Apoyo \\
\hline & & Crítica \\
\hline & & Rechazo \\
\hline & & Replicación \\
\hline & & Concienciación \\
\hline & & Constatación \\
\hline $\begin{array}{l}\text { Espacio que ocupa en la edición } \\
\text { impresa }\end{array}$ & \multicolumn{2}{|l|}{ Número de módulos ocupados en página } \\
\hline
\end{tabular}

Fuente: Elaboración propia

\subsection{Alcance de la muestra}

La muestra objeto de estudio ha incluido 350 ejemplares completos del Diario Información en su edición de Alicante, sacados a la venta entre el 3 de febrero de 2020

Vivat Academia. Revista de Comunicación. 2022, nº 155, 23-38 
Mula-Grau, J. y Cambronero-Saiz, B.

Identificación de las fake news que se publican en la edición en papel de un diario provincial en la era de la desinformación digital de Trump y el inicio del COVID

y el 21 de enero de 2021 (31 de marzo, 25 de diciembre y 1 no hubo edición de periódico porque son festivos de descanso muy señalados en España los días previos: Viernes Santo, Nochebuena y Nochevieja).

Como criterios de inclusión se han seleccionado todas las noticias y opiniones que versaban principalmente o hacían alguna referencia tangencial sobre fake news y/o noticias falsas e/o infoxicación, mientras que como criterios de exclusión se han desestimado aquellas páginas dedicadas a la parrilla de televisión, que hacían referencia solo al título o contenido de programas o películas sobre este hecho o sinopsis de películas o series que tuvieran que ver con el asunto objeto de estudio.

El trabajo plantea un análisis que aborda distintas dimensiones de los contenidos (Piñuel Raigada, 2002), de manera que funcione como vial que absorbe lo que realmente nos interesa sobre el conjunto de artículos que conforman a diario un periódico impreso.

Para ello, tras un primer cribado, se llevó a cabo un examen de las unidades que realmente se entendieron que tienen valor y hacen referencia directa a la cuestión de fondo mediante la elaboración de dos fichas de análisis y cálculo:

1. Ficha cuantitativa. Es la que va a indicar el número de unidades informativas o de opinión que hacen referencia a palabras clave como fake news, covid, Trump, infoxicación e ideas y conceptos como desinformación, noticias falsas y alteración de la verdad o similares.

2. Ficha cualitativa. Es la que va a permitir conocer en qué secciones aparecen los conceptos que interesan, la frecuencia, quiénes son los protagonistas directos o indirectos o a qué hechos o acontecimientos se asocian, así como qué tipo de género periodístico se emplea para plasmar el asunto en fondo en la edición impresa.

La investigación arranca con un trabajo previo de hemeroteca centrado en el Diario Información de Alicante, de ámbito provincial y local (1.879 888 habitantes en 2020) y el único impreso con estas características que existe actualmente para las personas lectoras alicantinas. Se examinan todas sus secciones, incluidas portada y contraportada, así como suplementos periódicos, como por ejemplo Arte y Letras. Previamente también se ha efectuado un análisis bibliográfico para entender correctamente los conceptos a identificar.

La investigación se justifica en conocer cómo, dónde y cuándo las fake news se convierten en noticia en sí mismas de cara a un lector de un periódico provinciallocal y por qué el gatekeeper considera que son de interés para una audiencia que aspira a que "su" periódico le cuente lo que ocurre cerca de donde vive o trabaja. Las fake news, desconocidas hasta hace unos años, se han vuelto un asunto de discusión casi diario en los medios de comunicación españoles, sobre todo a través de las redes sociales, cadenas de televisión y de radio de ámbito nacional, pero ¿esto también se traslada a un ámbito local mediante un periódico local? ¿Recoge también el diario de una localidad determinada o de una provincia concreta fake news locales o

Vivat Academia. Revista de Comunicación. 2022, nº 155, 23-38 
Mula-Grau, J. y Cambronero-Saiz, B.

Identificación de las fake news que se publican en la edición en papel de un diario provincial en la era de la desinformación digital de Trump y el inicio del COVID

provinciales? ¿Las hay? Estas fueron otras preguntas que fueron surgiendo conforme se avanzaba en la investigación.

\section{RESULTADOS}

El número de artículos donde las fake news han sido objeto de interés noticioso en este diario local-provincial a lo largo de casi un año asciende a 58, es decir casi una media de una vez a la semana solo. De estos, 10 artículos $(17,2 \%)$ tienen que ver con fake news y pandemia; 8 artículos $(13,7 \%)$ ponen en relación las fake news y el covid con el contexto local/provincial y otros tantos se vinculan a otros asuntos de fake news que no tienen que ver con ninguna de la categorías establecidas; 6 artículos $(10,3 \%)$ tratan acerca de estrategias para frenar las noticias falsas, la misma cifra que la relación fake news-política nacional; mientras que en 5 artículos (8,6\%) se aborda la desinformación a través de críticas sobre producciones audiovisuales. (ver Tabla 2).

Tabla 2. Temática de las noticias publicadas en el Diario Información relacionadas con las fake news $(03 / 02 / 20$ - 21/01/21)

\begin{tabular}{|l|l|l|}
\hline Temática de la noticia & Frecuencia & Porcentaje \\
\hline Política nacional y fake news & 6 & 10,3 \\
\hline COVID y fake news en contexto local & 8 & 13,7 \\
\hline Estrategias para frenar las fake news & 6 & 10,3 \\
\hline Fallecimientos falsos & 1 & 1,7 \\
\hline Estado de salud de la población & 1 & 1,7 \\
\hline Bolsonaro & 1 & 1,7 \\
\hline Jóvenes y fake news & 1 & 1,7 \\
\hline Enseñanza y fake news & 2 & 3,4 \\
\hline Historia y fake news & 3 & 5,1 \\
\hline Campañas electorales y fake news & 1 & 1,7 \\
\hline Críticas de TV o Cine & 5 & 8,6 \\
\hline Trump-covid-periodismo & 2 & 3,4 \\
\hline Trump-covid-Fake news & 1 & 1,7 \\
\hline Fake news y pandemia & 10 & 17,2 \\
\hline Trump-Fake news & 2 & 3,4 \\
\hline Fake News (otras) & 8 & 13,7 \\
\hline Total: & 58 & 100 \\
\hline
\end{tabular}

Fuente: Elaboración propia

Las alusiones restantes, con un porcentaje menor de visibilidad, son, además de parcas en número, también en lo concerniente a profundidad y abordaje.

En cuanto a los géneros en que resultan plasmados estos artículos, se encuentran a la cabeza de todos ellos aquellos que son tema central de opiniones y tribunas (21), noticias (16), reportajes (8), críticas de televisión o cine (7) y entrevistas (6).

Por secciones, los artículos relacionados con las fake news aparecen sobre todo en las páginas de Opinión/Tribuna (19), Local/Al Día/Estado de Alarma (13),

Vivat Academia. Revista de Comunicación. 2022, nº 155, 23-38 
Mula-Grau, J. y Cambronero-Saiz, B.

Identificación de las fake news que se publican en la edición en papel de un diario provincial en la era de la desinformación digital de Trump y el inicio del COVID

Cultura/Sociedad (7), Nacional (5), Última (5), Internacional (3), páginas de autopromoción (3), suplemento de Artes y Letras (1), Economía (1) y Política (1).

De la dinámica periodística de este diario resalta la escasa importancia otorgada en términos de información preeminente por el diario a las cuestiones objeto de este estudio. No solo por la escasa frecuencia, sino también en lo que se refiere a la ubicación en el seno del periódico y a su extensión. A los hechos nos remitimos cuando las fake news son sobre todo asunto abordado en las opiniones y tribunas de colaboradores o autores externos, "ajenos" al periódico. O son incorporadas de manera secundaria en el conjunto del artículo. Por no hablar cuando este tipo de artículos los traducimos a módulos de espacio (una página se divide en diez módulos de alto por cinco de ancho, es decir, 50 módulos en total), momento en que se evidencia que proporcionalmente, a lo largo de casi todo un año, e incluso en el conjunto del ejemplar de un día, las referencias a fake news apenas ocupan espacio apreciable (nunca por encima del 1\% del total de páginas del ejemplar de la jornada), ni destacable en su conjunto, ni en su ubicación preeminente: es decir, rara vez aparece en portada o contraportada; o en las primeras páginas; o abriendo las principales secciones; $u$ ocupando las páginas impares y de color, que suelen ser las más valoradas por los periodistas y las más caras a la hora insertar anuncios publicitarios.

Pero es más, se observa incluso cómo las fake news aparecen en críticas de televisión o cine, es decir, de nuevo un género vinculado a la opinión, todo ello cuando, como ocurre en este periódico, no tienen que ver con contenidos de autopromoción del propio diario, de brand content.

Reportajes, noticias o entrevistas sobre las fake news escasean en el papel, y si se apuntan no es precisamente para introducir a la persona lectora en la última polémica de Trump o el covid en relación con las fake newss, sino más bien en bulos que tienen que ver con temas muy locales o provinciales, en su gran parte alejadas de la política norteamericana o la pandemia mundial.

Por otra parte, sí hay algo que predomina absoluta y claramente en el enfoque de los artículos es el esfuerzo por denunciar, criticar, rechazar y concienciar sobre los perniciosos efectos de las fake news, ya sea a través de aportar información, opinión o contenidos de autopromoción. Se puede decir que la interpretación de un tono crítico es utilizada en el 100\% de los elementos analizados. Lejos queda de este periódico, al menos a la vista del estudio realizado, cualquier ánimo de contribuir o dar voz a corrientes favorecedoras de fake news y, por tanto, amplificarlas.

En definitiva, la "desinformación" apenas es servida a la audiencia de Información en papel. Lo que se publica es desde una perspectiva de denuncia, principalmente desde los géneros de la opinión, buscando a ser posible el enfoque o la percha local y sin contribuir a la reproducción del ruido mediático al respecto que emana de las convulsas redes sociales. Es como si el papel de este diario fuera una isla a la que solo llegara un exiguo eco de la infoxicación digital.

Vivat Academia. Revista de Comunicación. 2022, nº 155, 23-38 
Mula-Grau, J. y Cambronero-Saiz, B.

Identificación de las fake news que se publican en la edición en papel de un diario provincial en la era de la desinformación digital de Trump y el inicio del COVID

\section{DISCUSIÓN}

Los artículos relacionados con las fake news están en medio de la vorágine informativa. Precisión, equilibrio y coherencia no son atributos precisamente de las fake news, pero sí del periodismo, lo que no significa que sea una tarea sencilla. Lo fácil es desviarse del camino. La falta de espacio en papel, la cada vez mayor escasez de medios humanos, el modelo de negocio periodístico en crisis desde hace más de una década y los efectos de la actual pandemia en la economía de las empresas, incluidas las informativas, debilitan la calidad de las informaciones que se sirven. Precisamente, ahora más que nunca se precisan medios rigurosos e informaciones veraces que contribuyan a la masa crítica de la opinión pública.

Los artículos puestos bajo la lupa en este trabajo (58) introducen informaciones en torno a las fake news de forma poco detallada en algunas de las características analizadas, siendo la desinformación-pandemia, fake news-ambito provincial, las estrategias para frenar esta "lacra" y la política nacional los temas con los que más se relacionan este tipo de noticas, en consonancia en parte con los resultados de otros artículos (Román et al., 2020). Los ejemplos de denuncia, crítica y concienciación sobre las fake news se han encontrado mayoritariamente en los artículos de opinión o en las tribunas. Es aquí donde se alcanza mayor exhaustividad, mientras que en las noticias apenas se enumeran los aspectos peyorativos de las fake news. Es decir, ciertas informaciones no entran al detalle en explicar por qué una fake news debe ser invalidada, principalmente pensando en lo que se refiere a la manipulación, las explicaciones sencillas a problemas complejos, tomar la parte por el todo, su desmontaje con argumentos o profundizando en los riesgos que implican. Es en los artículos con firma externa, los colaboradores de la opinión, las plumas de tribuna las que fundamentalmente se adentran en los efectos perniciosos de las fake news en distintos sentidos. También es verdad que es la tribuna o la opinión donde el autor tiene más libertad y no se debe a la construcción de la noticia según los cánones establecidos.

Los resultados revelan sobre todo que las fake news son escasamente noticia en este diario local, no solo por su "infrecuencia", sino también porque no ocupan espacios preeminentes: rara vez está en los titulares y abundantemente aparecen como tema secundario o incluso terciario.

Sería pertinente y necesario agendarnos el poder extender este mismo trabajo a los otros tres años de la era Trump para comprobar si las fake news en la prensa local alicantina fueron noticia in crescendo o, por el contrario, se quedaron al margen de la actualidad para una audiencia local. De igual modo, se llegó a plantear la posibilidad de hacer un estudio similar en paralelo con un diario de Estados Unidos que cubra una población similar a la de la provincia de Alicante. No obstante, las dificultades de acceder desde España telemáticamente a hemerotecas que incluyan ediciones impresas digitalizadas, ni siquiera a través del portal Chronicling America, condujeron a abandonar dicha misión.

Vivat Academia. Revista de Comunicación. 2022, nº 155, 23-38 
Por tanto, a la pregunta de qué noticias sobre fake news se publican para un lector local en la era Trump-covid, una respuesta podría ser que la relación de frecuencia es elevadamente escasa en comparación con el corpus de noticias restante, pero además cabe incidir en que es más materia de los géneros de opinión que de los géneros de información, y que el ruido mediático y la batalla masiva que se libra en los social media en torno a este tema apenas tiene traslado o eco en lo que se conoce y entendemos como un diario de provincias.

\section{REFERENCIAS}

Allcott, H., \& Gentzkow, M. (2017). Social media and fake news in the 2016 election. Journal of economic perspectives, (31), 211-236. https://www.jstor.org/stable/i40177264

Alterman, E. (2004). When Presidents Lie: A History of Official Deception and Its Consequences. Penguin Books.

Arceneaux, N., \& Weiss A. S. (2010). Seems stupid until you try it: Press coverage of Twitter, 2006-9. New media and society, 12(8), 1262-1279. https://doi.org/10.1177/1461444809360773

Cárdenas Rica, M. L., y Polo Serrano, D. (2019). La posverdad: Una cartografía de los medios, la redes y la política. Gedisa

Casals Carro, M. J. (2000). La columna personal: de esos embusteros días del ego inmarchitable. Estudios sobre el mensaje periodístico, 6, 31-51. https://revistas.ucm.es/index.php/ESMP/article/view/ESMP0000110031A

Centro de Coordinación de Alertas y Emergencias Sanitarias (s. f.) Situación actual. Resumen de la situación. https:// bit.ly/3qI57oP

Costa-Sánchez, C. (2011). Tratamiento informativo de una crisis de Salud pública: los titulares sobre la gripe A en la Prensa Española. Revista de Comunicación de la SEECI, 25, 29-42. https://doi.org/10.15198/seeci.2011.25.29-42

De Pablo, I. (2018, 2 de febrero). Solo 14\% de españoles sabe distinguir un "fake", pero $60 \%$ cree que puede. La Vanguardia. https://n9.cl/yiv0

Departamento de Seguridad Nacional del Gabinete de la Presidencia del Gobierno de España. (s. f.). Coronavirus (2019-nCoV) - 03 de febrero de 2020. https://bit.ly/3vhkV5v

Fernández Gil, J. R. (2010). Fuentes de análisis para el estudio de la prensa. Anales de Documentación, 13 , 135-158. https://revistas.um.es/analesdoc/article/view/107101 
Mula-Grau, J. y Cambronero-Saiz, B.

Identificación de las fake news que se publican en la edición en papel de un diario provincial en la era de la desinformación digital de Trump y el inicio del COVID

Jackson, N., \& Lilleker, D. (2011) Microblogging, Constituency Service and Impression Management: UK MPs and the Use of Twitter. The Journal of Legislative Studies, 17 (1), 86-105. https:// doi.org/10.1080/13572334.2011.545181

Keyes, R. (2004). The Post-Truth Era: Dishonesty and Deception in Contemporary Life. St. Martin's Press.

Lewandowsky, S., Ecker, U. K. \& Cook, J. (2017). Beyond Misinformation: Understanding and Coping with the "Post-Truth" Era. Journal of Applied Research in Memory and Cognition, 6 (4), 353-369.

https://doi.org/10.1016/j.jarmac.2017.07.008

Lippmann, W. (2003). La opinión pública. Langre

McIntyre, L. (2018). Posverdad. Cátedra.

McNair, B. (2018). Fake news, falsehood, fabrication, and fantasy in journalism. Routledge.

Murolo, L. (2019). La posverdad es mentira. Un aporte conceptual sobre periodismo y fake news. En R. Aparici y D. García-Marín (Eds.), La posverdad. Una cartografía de los medios, las redes y la política. Gedisa.

Pérez Serrano, G. (1984). El análisis de contenido de la prensa. UNED

Piñuel Raigada, J. L. (2002). Epistemología, metodología y técnicas del análisis de contenido. Estudios de Sociolingüística. 3(1) 1-41. https://bit.ly/2Ox0ZuT

Redacción (2020, 12 de abril). Líderes en los momentos más duros. Información https://bit.ly/31cBtHb

Renda, A. (2018). The Legal Framework to Address "Fake News": Possible Policy Actions at the EU Level. Document prepared for Policy Department for Economic, Scientific and Quality of Life Policies. European Parliament. https://bit.ly/38H8zt]

Rodríguez-Ferrándiz, R. (2019). Posverdad y fake news en comunicación política: breve genealogía. El profesional de la información, 28 (3). https:// doi.org/10.3145/epi.2019.may.14

Román-San-Miguel, A., Valenzuela, N. S. G. y Zambrano, R. E. (2020). Las fake news durante el Estado de Alarma por COVID-19. Análisis desde el punto de vista político en la prensa española. Revista Latina de Comunicación Social, (78), 359-391.

Rubio Ferreres, J. M. (2009). Opinión pública y medios de comunicación. Teoría de la agenda setting. Gazeta de Antropología, 25(1) 1-17. https://bit.ly/3bIY23c 
Mula-Grau, J. y Cambronero-Saiz, B.

Identificación de las fake news que se publican en la edición en papel de un diario provincial en la era de la desinformación digital de Trump y el inicio del COVID

Ruchansky, N., Seo, S., \& Liu, Y. (2017). CSI: A Hybrid Deep Model for Fake News Detection. CIKM '17 Proceedings of the 2017 ACM on Conference on Information and Knowledge Management, 797-806. http://doi.org/dntn

San Miguel, A. y Sánchez-Gey, N. (2020). Tratamiento informativo de las fake news y su relación con los remedios falsos difundidos por Donald Trump durante el Estado de Alarma por el COVID-19. Comunicación, Periodismo y Publicidad: retos profesionales en tiempos de crisis (140), pp. 205-217. Fragua

Simple Lógica (s. f.). I Estudio sobre el Impacto de las Fake News en España. https://n9.cl/jwdm9

Vosoughi, S., Deb, R., \& Sinan, A. (2018). The spread of true and false news online. Science, 359(6380), 1146-1151. http:// doi.org/gc3jt6

\section{AUTORES:}

\section{Jesús Mula-Grau:}

Doctor en Estudios e Investigación sobre las Mujeres, Feministas y de Género por la Universidad Miguel Hernández de Elche. Máster en Igualdad de Género en el Ámbito Público y Privado por las universidades Miguel Hernández de Elche y Jaume I. Licenciado en Ciencias de la Información especialidad Periodismo por la Universidad Politécnica de Valencia. Profesor de Redacción Periodística I, Redacción Periodística II, Periodismo Científico y Medioambiental en el grado de Periodismo y doble grado de Comunicación Audiovisual y Periodismo de la Universidad Miguel Hernández de Elche, y de Comunicación Corporativa en el centro universitario Instituto Mediterráneo de Estudios de Protocolo IMEP adscrito a la UMH. Coorganizador de un congreso internacional, ponente en distintos eventos congresuales y autor de distintas publicaciones y capítulos de libros relacionados con la comunicación, el género y el periodismo.

ORCID: https://orcid.org/0000-0001-5100-9492

\section{Belén Cambronero-Saiz:}

Licenciada en Publicidad y Relaciones Públicas (UA) y Doctora en Estudios Pluridisciplinares de Género (líneas de Comunicación y Salud) (UA). Ha trabajado como investigadora FPI en el departamento de Comunicación y Psicología Social de la UA. En esta misma universidad ha participado en numerosos proyectos $\mathrm{I}+\mathrm{D}+\mathrm{i}$ y grupos de investigación, publicando más de una decena de artículos centrados en salud, comunicación y género. Desde 2016, trabaja como PDI en UNIR impartiendo docencia en Grado y Posgrado, y llevando la Coordinación Académica de Prácticas de la Facultad de Empresa y Comunicación de esta misma universidad. Como investigadora y docente ha realizado estancias en diferentes universidades de Europa, Australia y América Latina fortaleciendo su vínculo con universidades extranjeras.

ORCID: https:// orcid.org/0000-0001-5273-9534 